\title{
Aslanpençesi (Alchemilla ellenbergiana) Ekstrelerinin Antioksidan ve Antimikrobiyal Özelliklerinin Belirlenmesi
}

\author{
Determination of Antioxidant and Antimicrobial Properties of Lady's Mantle (Alchemilla \\ ellenbergiana) Extracts
}

\author{
Tuba ACET*1,a, Kadriye ÖZCAN ${ }^{2, b}$ \\ ${ }^{1}$ Gümüşhane Üniversitesi, Mühendislik ve Doğa Bilimleri Fakültesi, Genetik ve Biyomühendislik Bölümü, 29100, Gümüşhane \\ ${ }^{2}$ Giresun Üniversitesi, Mühendislik ve Doğa Bilimleri Fakültesi, Genetik ve Biyomühendislik Bölümü, 28200, Giresun
}

• Geliş tarihi / Received: 24.04.2017 • Düzeltilerek geliş tarihi / Received in revised form: 20.11.2017 • Kabul tarihi / Accepted: 21.11.2017

\begin{abstract}
Öz
Bu çalışmada, Gümüşhane bölgesi halk tıbbında kullanılan Alchemilla ellenbergiana (aslanpençesi) bitkisinin farklı polariteye sahip çözücülerle (hekzan, etil asetat, etanol ve metanol) hazırlanmış ekstrelerinin toplam fenolik miktarları, antioksidan ve antimikrobiyal aktiviteleri araştırıldı. Toplam fenolik miktarı gallik asit eşdeğeri olarak spektrofotometrik yöntemle ölçüldü ve en yüksek değerler metanol ve etanol ekstrelerinde tespit edildi. Ekstrelerin antioksidan aktiviteleri ABTS [2,2'-azino-bis (3-etilbenzotiazolin-6-sülfonik asit)] ve DPPH (2,2-difenil-1pikrilhidrazil) yöntemleriyle spektrofotometrik olarak belirlendi ve troloks eşdeğeri olarak hesaplandi. Antimikrobiyal aktivite disk difüzyon yöntemiyle patojen mikroorganizmalar üzerine test edildi. Sonuç olarak bitkinin etanol ve metanol ekstrelerinin antioksidan aktivitesi diğer ekstrelerden anlamlı olarak yüksek bulundu $(\mathrm{p}<0.05)$. Benzer olarak, etanol ve metanol ekstrelerinin antimikrobiyal aktivitesi de diğer eksterelerden yüksek bulundu.
\end{abstract}

Anahtar kelimeler: ABTS, Alchemilla ellenbergiana, antimikrobiyal aktivite, antioksidan aktivite, disk difüzyon, DPPH

\begin{abstract}
In this study, different polarity solvent (hexane, ethyl acetate, ethanol and methanol) extracts of Alchemilla ellenbergiana (Lady's Mantle), which used in folk medicine plant in Gümüşhane region, were investigated in terms of total phenolic contents, antioxidant and antimicrobial activity. Total phenolic contents were measured by spectrophotometric metod as gallic acid equivalent and detect in the highest in ethanol and methanol extracts. Antioxidant activity of extracts were determined by ABTS [2,2'-Azino-bis(3-ethylbenzothiazoline-6-sulfonic acid) diammonium salt] and DPPH (2,2-diphenyl-1-picrylhydrazyl) methods by spectrophotometric metod and calculated as trolox equivalent. Antimicrobial activity was tested against to pathogen microorganisms by disc diffusion method. As a result, it has been found that ethanol and methanol extracts of plant have high antioxidant and antimicrobial activity $(p<0.05)$. Similarly, it has been found that antimicrobial activity of ethanol and methanol extracts higher than others.
\end{abstract}

Keywords: ABTS, Alchemilla ellenbergiana, antimicrobial activity, antioxidant activity, disc diffusion, DPPH

\footnotetext{
*a Tuba ACET; tubaacet@hotmail.com; Tel: (0 456) 2331000 (dahili: 1881); orcid.org/000-0002-0981-9413

${ }^{\mathrm{b}}$ orcid.org/0000-0002-4913-6035
} 


\section{Giriş}

Ülkemizde genellikle "aslanpençesi" adıyla bilinen Alchemilla L. cinsi Rosaceae (Gülgiller) familyasına ait çok yıllık otsu bir bitkidir. 1000 'den fazla tür ile temsil edilen Alchemilla cinsi genellikle holarktik yayılış göstermekle beraber, Etiyopya'nın Ümit Burnu'ndan, Doğu Afrika Dağları'na kadar, Madagaskar, Güney Hindistan, Seylan ve Cava adası bölgelerinde bulunmaktadır (Izmailow, 1981). Alchemilla'nın Avrasya taksonları Rothmaler tarafindan iki seksiyona ayrılmıştır. $\mathrm{Bu}$ seksiyonlar Pentaphyllon Rothm. ve Brevicaulon Rothm.'dur. Aynı araştırıcıya göre bunlara ait taksonların bir kısmı geniş yayılışlı, bir kısmı da endemiktir (Rothmaler ve Repert, 1937). Türkiye florasındaki kayıtlara göre, Türkiye'de yayılış gösteren Alchemilla türlerinin tamamı Alchemilla seksiyonuna aittir. $\mathrm{Bu}$ seksiyon 3 subseksiyon (Chirophyllum Rothmn, Heliodrosium Rothmn ve Calycanthum Rothmn) ve 6 seriye (Saxatiles Bus, Sericeae Bus, Pubescentes Bus, Vulgares Bus, Elatae Rothmn ve Calycinae Bus) ayrılmıştır (Hayırlığlu vd., 1997). Bunların pek çoğu Kuzey Anadolu'da bulunmaktadır (Davis, 1970). Özellikle, iklimsel ve coğrafi özellikleri bakımından farklı özeliklere sahip Gümüşhane ilinin sarp yamaçlarında Alchemilla ellenbergiana ROTHM. türü, 2000-3000 m. yüksekliklerde geniş yayılış göstermektedir (Tubives) ve bölge halkı tarafından tıbbi amaçlı olarak kullanılmaktadır.

Literatürde de, Alchemilla türlerinin pek çok bölgede kullanıldığ 1 ve antioksidan, antimikrobiyal, diüretik, tonik, üreme bozukluklarını giderici, hücre yenileyici ve antidiyabetik olmak üzere pek çok önemli özelliği olduğu ileri sürülmüştür (Viegi vd., 2003; Altundag ve Öztürk, 2011; Kaya ve Arturan, 2016; Ozbek vd., 2017).

Bitkiler, hayatın sürdürülebilmesi için, başlıca besin kaynağı olmasının yanı sıra, sağlığımız için oldukça önemli olan fenolik ve flavonoidler gibi çeşitli fitokimyasallar da içerirler (Gülçin vd., 2011). İçerdikleri zengin fitokimyasallar onların yüzyıllar boyunca kullanılmalarını sağlamıştır ve günümüzde de pek çok ilaç tıbbi bitkilerden elde edilmektedir (Ozdemir ve Alpınar, 2015). Ayrıca, Dünya Sağlık Örgütü'nün raporlarına göre, dünya nüfusunun \% 80'i öncelikli sağlık bakımı için bitkisel ilaçları kullanmaktadır (Güler vd., 2015). Son yıllarda, çeşitli etnobotanik çalışmalardan söz edilmiş olsa da (Güler vd., 2015; Paksoy vd., 2015; Sargin, 2015) özellikle Gümüşhane bölgesinde kullanılan tıbbi bitkilerin bilimsel kaydı henüz net değildir. Bu nedenle, yaptığımız çalışma ile Gümüşhane ilinde halk arasında yara iyileştirici, iltihap kurutucu veya besin katkısı gibi amaçlarla, çeşitli yöntemler ile kullanılan aslanpençesi bitkisinin antioksidan ve antimikrobiyal özelliklerinin ortaya çıkarılması amaçlanmıştır. $\mathrm{Bu}$ çalışma, Gümüşhane ilinde yay1lış gösteren Alchemilla ellenbergiana türüne ait yapılmış ilk çalışmadır.

\section{Materyal ve Metod}

\subsection{Bitkilerin eldesi}

Bitkiler Artabel eteklerinde yer alan Gülaçar köyü sakinlerinden temin edildi. Tür tayini, Gümüşhane Üniversitesi, Genetik ve Biyomühendislik Bölümü'nde oluşturmuş olduğumuz bitki herbaryumunda TAA 1605 kodu ile muhafaza edilerek; "Rothmaler in Repert. Spec. Nov. Regni Veg. 50. 1941" nomenklatür referansi temel alınarak Yrd. Doç. Dr. Tuba ACET tarafından yapıldı. Toplanan bitkiler direkt güneş ışığına maruz birakılmadan 2 hafta boyunca kurutuldu ve kurutulmuş bitkiler mekanik ögütücü (Fritsch P15 , Germany) yardımıyla toz haline getirildi.

\subsection{Bitki Ekstrelerinin Eldesi}

Bitki ekstre eldesi için toz haldeki bitki parçacıkları kullanılmıştır. Ekstraksiyon için farklı polariteye sahip hekzan (Merck), etil asetat (Merck), etanol (Merck) ve metanol (Merck) tercih edilmiștir. Ekstraksiyon, $10 \mathrm{~g}$ bitki üzerine $200 \mathrm{ml}$ solvent eklenerek $37^{\circ} \mathrm{C}, 125 \mathrm{rpm}$ 'de 24 saat boyunca çalkalanarak gerçekleştirilmiştir. 24 saat sonra kăğt kaba filtre yardımıyla bitki parçacıkları solventten uzaklaştırılmıştır. Vakum altında $37^{\circ} \mathrm{C}$ 'yi aşmayan sicaklıkta solvent evaporatör (Heidolf) yardımıyla uzaklaştırılmış ve elde edilen kuru ekstre analizlerde kullanılmak üzere $4^{\circ} \mathrm{C}^{\prime}$ de muhafaza edilmiştir. Toplamda 4 ekstre elde edilmiştir. Her ekstre için $10 \mathrm{mg} / \mathrm{ml}$ stok solüsyon DMSO (dimetil sülfoksit-Sigma Aldrich) kullanılarak hazırlanmış ve analizlerde stok solüsyon kullanılmıştır.

\subsection{Toplam Fenolik Tayini}

Ekstrelerin toplam fenolik içeriği Folin-Ciocaltaeu yönteminde küçük değişiklikler yapılarak spektrofotometrik olarak ölçülmüştür (Slinkard vd., 1977). Yöntem üzerinde küçük değişiklikler yapılmış ve 2 saat oda sıcaklı̆̆ında bekletilerek $750 \mathrm{~nm}$ dalga boyunda mikroplaka okuyucu (Biorad) ile ölçüm yapılmıştır. Reaksiyon $31.25 \mu \mathrm{l}$ 
ekstre solüsyonu, $125 \mu$ l folin reaktifi (1:9) ve $93.75 \mu \mathrm{l} \% 1$ sodyum karbonat $\left(\mathrm{Na}_{2} \mathrm{CO}_{3}\right)$ eklenerek toplamda $250 \mu \mathrm{l}$ hacimde mikroplaka kullanılarak gerçekleştirilmiştir. $5-150 \quad \mu \mathrm{g} / \mathrm{ml}$ konsantrasyon aralığında gallik asit standart eğrisi oluşturulmuş ve hesaplamalar standart eğrisi referans alınarak yapılmıştır. Toplam fenolik miktarı gallik asit eşdeğeri mg GAE/g ekstre olarak hesaplanmıştır.

\subsection{Antioksidan Aktivite Tayini}

\subsubsection{ABTS Yöntemi}

Örneklerin antioksidan kapasitesi Re ve ark., (1999) tarafindan geliştirilen spektrofotometrik ölçüm yönteminde küçük değişiklikler yapılarak belirlenmiştir. Kısaca, 7mM ABTS [(2,2'-azinobis (3-etilbenzotiazolin-6-sülfonik asit)] ve 2.45 $\mathrm{mM}$ potasyum persülfat $\left(\mathrm{K}_{2} \mathrm{~S}_{2} \mathrm{O}_{8}\right)$ kullanılarak ABTS solüsyonu (OD: 0.7 ) hazırlanmış ve antioksidan aktivite tespitinde kullanılmıştır. $80 \mu 1$ ekstre solüsyonu üzerine $160 \mu 1 \mathrm{ABTS}$ solüsyonu eklenerek 6. dakikada mikroplaka okuyucuda 750 $\mathrm{nm}$ dalga boyunda ölçüm yapılmıştır. Troloks standart eğrisi çizilmiş ve sonuçlar troloks eşdeğeri olarak hesaplanmıştır. DPPH radikali giderme aktivitesi \% inhibisyon değerleri ise aşağıda verilen formül ile hesaplandı:

$\%$ İnhibisyon $=\left[\left(\mathrm{A}_{\text {Kontrol }}-\mathrm{A}_{\mathrm{Ekstre}}\right) / \mathrm{A}_{\text {Kontrol }} \mathrm{X} 100\right]$

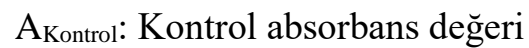

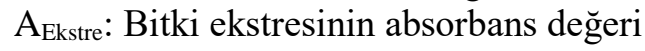

ABTS'nin \% 50'sinin inhibisyonunu sağlayan ekstre ve standart madde konsantrasyonu $\mathrm{IC}_{50}$ olarak tanımlanır. $\mathrm{Bu}$ değer, \% inhibisyon-ekstre konsantrasyonu grafiğinden elde edilen doğru denkleminden hesapland 1 ve sonuçlar $\mu \mathrm{g} / \mathrm{ml}$ olarak verildi.

\subsubsection{DPPH Yöntemi}

Örneklerin radikal süpürme aktivitesi (DPPH) Brand-Williams ve ark. (1995) tarafindan açıklanan yöntemde küçük değişiklikler yapılarak gerçekleştirilmiştir. Kısaca, metanol kullanılarak çözülen $0.1 \quad \mathrm{mM}$ DPPH (2,2-difenil-1pikrilhidrazil) kullanılarak spektrofotometrik olarak $490 \mathrm{~nm}$ dalga boyunda mikroplaka okuyucu ile ölçüm yapılmıştır. $125 \mu 1$ ekstre çözeltisi üzerine $125 \mu 1 \mathrm{DPPH}$ eklenmiş ve 45 dakika oda sıcaklığında bekletilerek ölçüm yapılmıştır. Standart olarak troloks kullanılmış ve sonuçlar troloks eşdeğeri olarak hesaplanmıştır.
DPPH radikali giderme aktivitesi \% inhibisyon değerleri ise aşağıda verilen formül ile hesaplandı:

$\%$ İnhibisyon $=\left[\left(\mathrm{A}_{\text {Kontrol- }} \mathrm{A}_{\mathrm{Ekstre}}\right) / \mathrm{A}_{\text {KontrolX }} 100\right]$

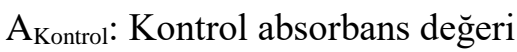

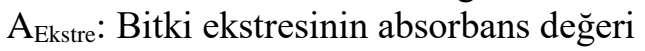

DPPH'in \% 50'sinin inhibisyonunu sağlayan ekstre ve standart madde konsantrasyonu $\mathrm{IC}_{50}$ olarak tanımlanır. Bu değer, \% inhibisyon-ekstre konsantrasyonu grafiğinden elde edilen doğru denkleminden hesaplandı ve sonuçlar $\mu \mathrm{g} / \mathrm{ml}$ olarak verildi.

\subsection{Antimikrobiyal Aktivite Tayini}

Ekstrelerin $10 \mathrm{mg} / \mathrm{ml}$ konsantrasyon stokları kullanılarak disk difüzyon yöntemiyle antimikrobiyal aktivite belirlenmiştir (CLSI, 2007). Enterococcus faecalis ATCC 29212, MRSA ATCC 43300, Pseudomonas aeruginosa ATCC 27853, Yersinia enterocolitica ATCC 27729, Vibrio parahaemolyticus ATCC 17802, Klebsiella pneumonie ATCC 13883, Candida albicans DSMZ 5817 ve Candida albicans ATCC 10231) test organizma olarak kullanıldı. Öncelikle test organizmaların taze kültürleri hazırlandı ve 0,5 MacFarland bulanıklığına seyreltilerek eküvyon yardımıyla Müller-Hinton agar petri üzerine inokülasyonu gerçekleştirildi. Test organizma uygulanmış petri üzerine $6 \mathrm{~mm}$ boş disk yerleştirildi ve disk üzerine $20 \mu 1$ ekstre solüsyonu emdirildi. Petriler 2 saat $4^{\circ} \mathrm{C}$ 'de bekletilerek ekstrelerin agara difüzyonu sağlandı. Pozitif kontrol olarak aynı konsantrasyonda kloramfenikol ve nistatin kullanıld. $37^{\circ} \mathrm{C}$ 'de 48 saat inkübasyon sonrasında diskler çevresinde oluşan zon çapları ölçüldü.

\section{3. İstatistiksel Analizler}

Tüm ölçümler 3 tekrarlı olarak gerçekleştirildi. Sonuçlar SPSS (version 11.5 for Windows 2000, SPSS Inc.) programinda, One-way ANOVA ile hesaplandı ve önemli farkl111klar Duncan'ın çoklu sira testleri ile belirlenip $\mathrm{p}<0.05$ değerleri anlamlı olarak kabul edildi.

\section{Bulgular ve Tartışma}

\subsection{Ekstre Verimi}

Bitki ekstraksiyonu için dört farklı polaritede solvent kullanılmıştır. Alchemilla ellenbergiana türüne ait bitkilerden takip eden ekstraksiyon ile elde edilen metanol, etanol, etil asetat ve hekzan 
ekstre verimleri Tablo 1'de verilmiştir. Ekstrelerin $\%$ verimi Tablo 1 de verildiği gibi en yüksek 10.3 olarak metanol ekstresinde elde edilirken en düşük $\%$ verim 1.6 olarak hekzan ekstresinde tespit edilmiştir.

Tablo 1. Alchemilla ellenbergiana' nın özüt verimleri

\begin{tabular}{|l|l|}
\hline Ekstraksiyon solventi & \% verim \\
\hline Metanol & 10.3 \\
\hline Etanol & 9.5 \\
\hline Etil asetat & 5.6 \\
\hline Hekzan & 1.6 \\
\hline
\end{tabular}

\subsection{Toplam Fenolik Miktarı}

Çözeltilerin absorbansları mikroplaka okuyucu da $750 \mathrm{~nm}$ 'de okunarak toplam fenolik miktarları; Şekil 1'de standart gallik asitle çizilen kalibrasyon eğrisinden (Şekil 1), mg gallik aside eşdeğer olacak şekilde hesaplandı. Ekstrelerin toplam fenolik miktarları farklılık göstermekte ve en yüksek fenolik içerik metanol ekstresi (777.2 $\mathrm{mg} / \mathrm{g}$ ekstre GAE) ve etanol ekstresinde (750 $\mathrm{mg} / \mathrm{g}$ ekstre GAE) bulunurken en düşük fenolik içerik ise hekzan ekstresinde $(47.5 \mathrm{mg} / \mathrm{g}$ ekstre GAE) tespit edilmiştir (Şekil 2).

Denev ve ark. (2014) Alcemilla glabra yaprakları aseton ekstresi ile yaptıkları çalışmada toplam fenolik miktarını $429 \mathrm{mg} / 100 \mathrm{~g}$ olarak rapor etmişlerdir. Yine, Alchemilla mollis ile yapılan bir araştırmada fenolik miktarı \%70 metanol ekstresinde $184.79 \mathrm{mg} \mathrm{GAE} / \mathrm{g}$ ekstre olarak tespit etmişlerdir (Karatoprak vd., 2017). Ayrıca, Alchemilla cimilensis bitkisi ile yapilan bir çalışmada en yüksek toplam fenolik miktarı etil asetat eksresinde $67.86 \mathrm{mg} \mathrm{GAE} / \mathrm{g}$ ekstre olarak bulunmuştur (Kaya ve Artuvan, 2015). Alchemilla ellenbergiana' nın diğer Alchemilla türlerinden daha yüksek fenolik miktarına sahip olduğu gözlemlenmiştir.
Şekil 1. Toplam fenol miktarı için gallik asit ile hazırlanan standart grafiği

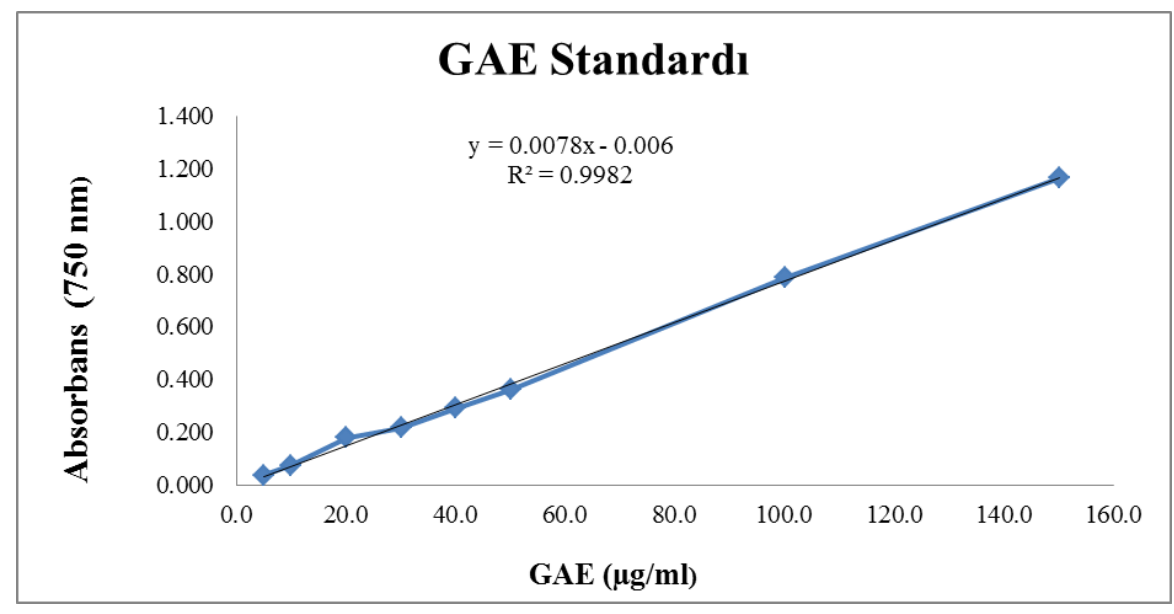

Şekil 2. Farklı çözücülerle hazırlanmış Alchemilla ellenbergiana ekstrelerinin toplam fenol miktarları.

a, b, c, d Aynı sütunda farklı harfle işaretlenmiş ortalamalar istatistiki olarak Duncan testine göre birbirinden farklıdır $\quad(\mathrm{p}<0.05)$. Sonuçlar 3 paralelin ortalaması alınarak, ortalama \pm standart sapma olarak verilmiştir.

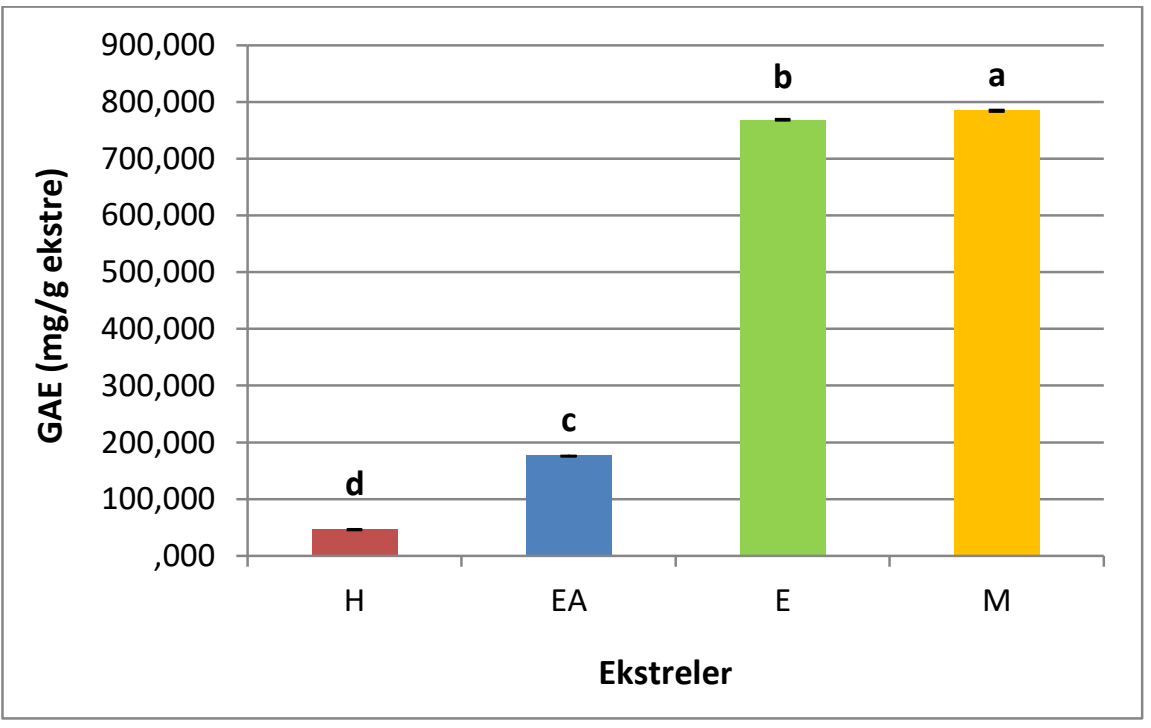




\subsection{Antioksidan Aktivite Tayini}

Farklı çözücüler ile elde edilen ekstrelerin antioksidan kapasitelerine, serbest radikallerin süpürülmesini ifade eden ABTS ve DPPH yöntemleri ile belirlendi. ABTS sonuçları, Şekil 3'te çizilen troloks grafiğine eşdeğer olacak şekilde hesaplandı ve buna göre grafik çizildi (Şekil 4). Yapılan hesaplamalarda ABTS radikal süpürme etkisi TAEC (troloks eşdeğerliği antioksidan kapasite) olarak hesaplanmış olup en yüksek TAEC değeri metanol ekstresinde (109.9 $\mu \mathrm{g} / \mathrm{ml})$ ve takiben etanol ekstresinde (100.2 $\mu \mathrm{g} / \mathrm{ml}$ ) bulunurken en düşük etki hekzan ekstresinde $(3.9 \mu \mathrm{g} / \mathrm{ml})$ tespit edilmiştir. Bitki ekstrelerine ait $\mathrm{IC}_{50}$ değerleri $39.88^{\mathrm{c}} \pm 1.54$ ile $187.64^{\mathrm{a}} \pm 1.79 \mu \mathrm{g} / \mathrm{ml}$ arasında bulunmuştur (Tablo 2). $\mathrm{IC}_{50}$ değerinin düşük değerde olmas1, ekstrenin ya da standartların ABTS radikali giderme aktivitelerinin yüksek olduğunu göstermektedir. Bu durumda, metanol ekstresinin ABTS radikali giderme aktivitesi, diğer ekstrelerden önemli derecede yüksektir. Metanol ekstresini etil asetat>etanol>hekzan takip etmektedir (Tablo 2).
Şekil 3. ABTS aktivitesi için Trolox ile hazırlanan standart grafiği
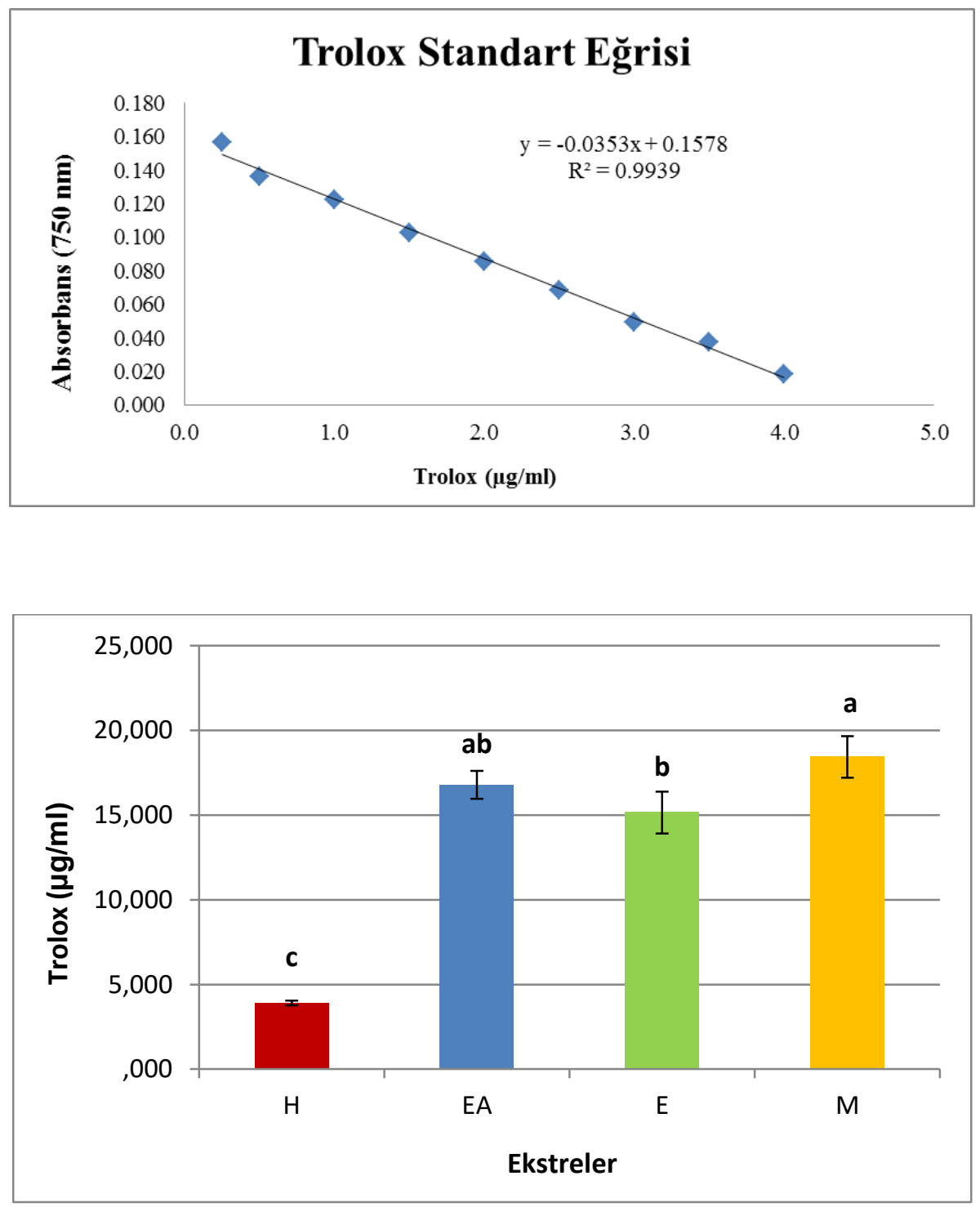

Şekil 4. Farklı çözücülerle hazırlanmış Alchemilla ellenbergiana ekstrelerinin ABTS değerleri a, b, c, d Aynı sütunda farklı harfle işaretlenmiş ortalamalar istatistiki olarak Duncan testine göre birbirinden farklıdır $(\mathrm{p}<0.05)$. Sonuçlar 3 paralelin ortalamas1 alınarak, ortalama \pm standart sapma olarak verilmiştir. belirlenmiştir (Tablo 2). Yapılmış farklı araştırmalarda Alchemilla türlerinin metanol ekstrelerinin antioksidan aktivitelerinin yüksek olduğu rapor edilmiştir (Usta vd., 2013; Denev vd., 2014). Denev ve ark. (2014)'nın Alchemilla glabra bitki ekstreleri üzerine yaptıkları çalışmalarda, DPPH aktivitesi $135 \mathrm{mg} / 100 \mathrm{~g}$ estre olarak bulunmuştur. Açıkça görülmektedir ki, 
DPPH metodunda çalışılan bitkide etanol ve metanol ekstreleri yüksek süpürücü etki göstermektedir.

Bitki ekstrelerine ait $\mathrm{IC}_{50}$ değerleri $27.46^{\mathrm{b}} \pm 0.03$ ile $144.34^{\mathrm{a}} \pm 1.70 \mu \mathrm{g} / \mathrm{ml}$ arasında bulunmuştur (Tablo 2). $\mathrm{IC}_{50}$ değerinin düşük değerde olması, ekstrenin ya da standartların ABTS radikali giderme aktivitelerinin yüksek olduğunu göstermektedir. $\mathrm{Bu}$ durumda, etanol, metanol ve etil asetat ekstrelerinin DPPH radikal süpürme etkileri anlamlı olarak birbirine yakın olup; yüksek aktivite göstermiştir. Hegzan aktivitesi ise diğerlerine göre oldukça düşük aktivite sergilemiştir. Elde edilen veriler, literatüre uygunluk göstermektedir. Örneğin, Alchemilla vulgaris bitkisi ile yapılmış bir çalışmada, metanol ekstresine ait $\mathrm{IC}_{50}$ değeri $19.62 \mu \mathrm{g} / \mathrm{ml}$ olarak bulunmuştur (Nikolova vd., 2012).
Şekil 5. DPPH aktivitesi için troloks ile hazırlanan standart grafiği

Şekil 6. Farklı çözücülerle hazırlanmış Alchemilla ellenbergiana ekstrelerinin DPPH değerleri a, b, c, d Aynı sütunda farklı harfle işaretlenmiş ortalamalar istatistiki olarak Duncan testine göre birbirinden farklıdır $(\mathrm{p}<0.05)$. Sonuçlar 3 paralelin ortalamas 1 alınarak, ortalama \pm standart sapma olarak verilmiştir.
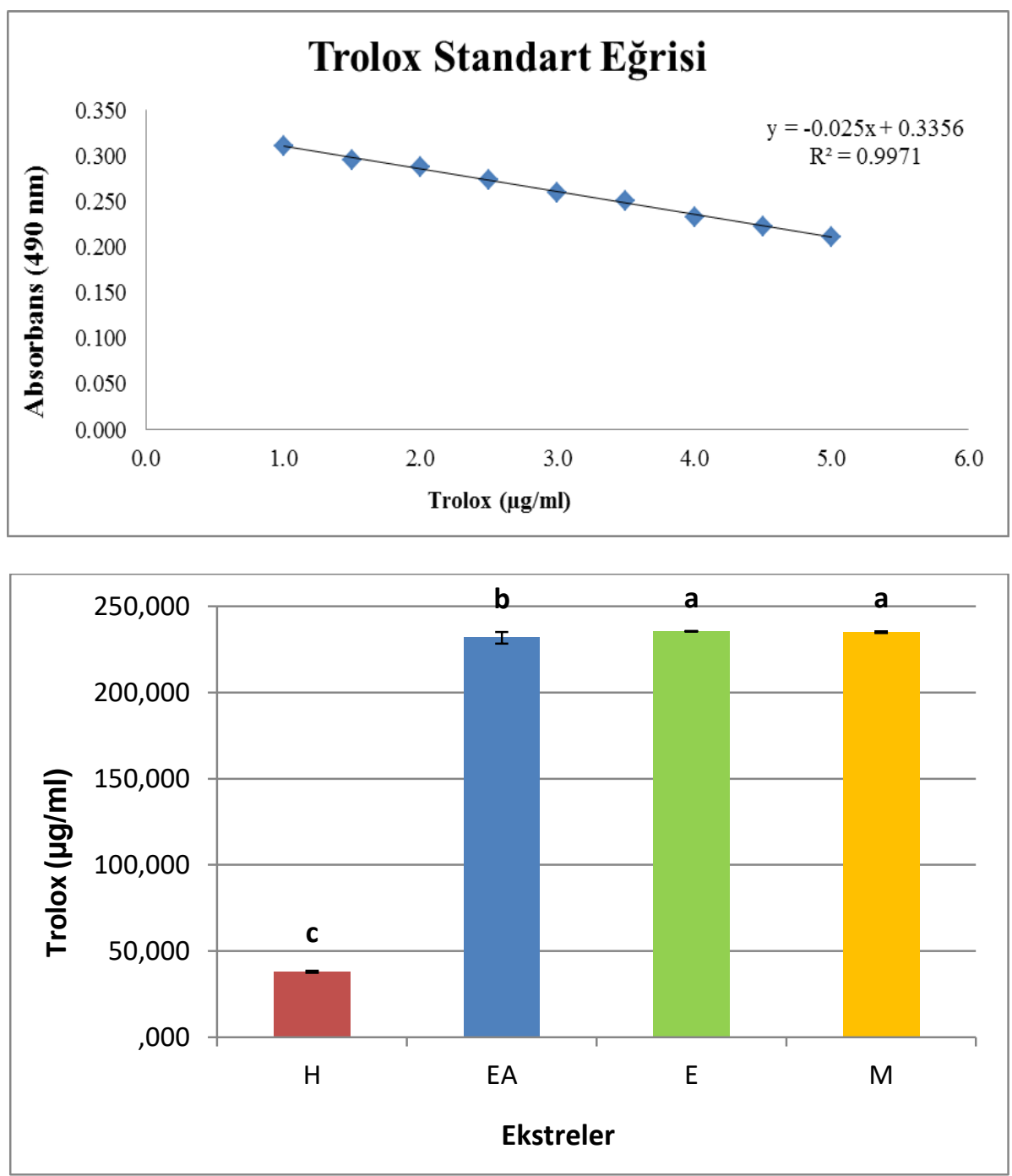

\subsection{Antimikrobiyal Aktivite Tayini}

Ekstrelere ait antimikrobiyal aktivite denemelerinde en iyi aktivite $P$. aeruginosa dışında tüm test organizmalara karşı inhibisyon gösteren etonol ekstresinde tespit edilirken en verimsiz sonuç tek organizmaya karşı aktivite ile hekzan ekstresinde bulunmuştur. Bitkinin etanol ekstresi Candida albicans (ATCC 10231) için pozitif kontrol nistatinden daha etkili bulunmuştur. Etil asetat ekstresi etanolden sonra en yüksek antimikrobiyal aktivite göstermiştir (Tablo 3). Tüm ekstrelerde Pseudomonas aeruginosa patojenine karşı etki görülmemiş ve bu nedenle Tablo 3'te bu organizmaya yer verilmemiştir. Alchemilla glabra ekstrelerinin antimikrobiyal aktivitesi üzerine yapılan çalışmada (Denev vd., 2014) da Salmonella enterica, Listeria monocytogenes ve Pseudomonas aerugenosa üzerine aktivite tespit edilmemiştir. 
Tablo 2: Ekstrelerin Antioksidan Aktiviteleri

\begin{tabular}{|c|c|c|}
\hline Ekstreler & ABTS IC $_{\mathbf{5 0}}(\boldsymbol{\mu g} / \mathbf{m l})$ & DPPH IC $_{\mathbf{5 0}}(\boldsymbol{\mu g} / \mathbf{m l})$ \\
\hline Hegzan & $187.64^{\mathrm{a}} \pm 1.79$ & $144.34^{\mathrm{a}} \pm 1.70$ \\
\hline Etil asetat & $43.68^{\mathrm{bc}} \pm 1.23$ & $28.05^{\mathrm{b}} \pm 0.59$ \\
\hline Etanol & $48.61^{\mathrm{b}} \pm 1.27$ & $27.46^{\mathrm{b}} \pm 0.03$ \\
\hline Metanol & $39.88^{\mathrm{c}} \pm 1.54$ & $27.52^{\mathrm{b}} \pm 0.05$ \\
\hline
\end{tabular}

\pm standart sapma, $\mathrm{n}=3$, sütunlardaki harfler $\mathrm{P}<0.05$ istatistiksel düzeyde ekstreler arasındaki önemli farklılıkları göstermektedir.

Tablo 3: Ekstrelere ait antimikrobiyal aktivite sonuçları (*inhibisyon zon çapı mm)

\begin{tabular}{|l|c|c|c|c|c|c|c|}
\hline & $\begin{array}{c}\text { E. } \\
\text { faecalis }\end{array}$ & MRSA & K.pneumoniea & $\begin{array}{c}\text { Y. } \\
\text { enterocolitica }\end{array}$ & $\begin{array}{c}\text { V. } \\
\text { parahaemolyticus }\end{array}$ & $\begin{array}{c}\text { C.albicans } \\
\text { DSMZ }\end{array}$ & $\begin{array}{c}\text { C. albicans } \\
\text { ATCC }\end{array}$ \\
\hline $\begin{array}{l}\text { Metanol } \\
\text { ekstresi }\end{array}$ & - & 12 & - & 12 & - & 14 & - \\
\hline $\begin{array}{l}\text { Etanol } \\
\text { ekstresi }\end{array}$ & 12 & 11 & 11 & 11 & 10 & 12 & 18 \\
\hline $\begin{array}{l}\text { Etil asetat } \\
\text { ekstresi }\end{array}$ & 14 & 13 & 11 & 12 & - & 12 & 13 \\
\hline $\begin{array}{l}\text { Hekzan } \\
\text { ekstresi }\end{array}$ & - & - & - & 10 & - & - & - \\
\hline Kloramfenikol & 15 & 15 & 12 & 12 & - & 10 & - \\
\hline Nistatin & - & - & - & - & & & 15 \\
\hline
\end{tabular}

Çalışmamızda, P. aerugenasa'ya karşı aktivite bulunmaması literatüre uygunluk göstermektedir. Yine aynı çalışmada, Staphylococcus aureus ve Klebsiella pneumoniea'ye karşı 9 mm, Candida albicans'a karşı $11 \mathrm{~mm}$ inhibisyon zonu gözlenmiştir. Bununla beraber, Alchemilla ellenbergia bitki ektrelerinin antimikrobiyal aktivitesinin daha yüksek olduğu bulunmuştur. Şöyle ki, etanol ekstresi Candida albicans üzerine $18 \mathrm{~mm}$ inhibisyon zonu ile kontrol olarak kullanılan nistatinden $(15 \mathrm{~mm})$ daha yüksek inhibisyon sergilemiştir. Ayrıca, metisilin dirençli S. aureus (MRSA) üzerine etil asetat ve metanol ekstreleri sirasiyla $13 \mathrm{~mm}$ ve $12 \mathrm{~mm}$ inhibisyon gösterirken; K. pneumoniea üzerine etanol ve etil asetat ekstreleri $11 \mathrm{~mm}$ ile eşit biçimde inhibisyon göstermişlerdir. $\mathrm{Bu}$ değerler, pozitif kontrol olan kloramfenikole yakın veya biraz düşük olsa da bahsedilen literatüre göre daha yüksek inhibisyonun gerçekleştiğini göstermektedir. Farklı Alchemilla türlerinin antimikrobiyal aktivitesinin araştırıldığı çalışmalarda farklı ekstrelerinin Gram (+) ve Gram (-) bakteriler ile Candida türleri üzerine etkili sonuçlar gösterdikleri tespit edilmiştir (Usta vd., 2013; Denev vd., 2014).

\section{Sonuç}

Alchemilla ellenbergiana bitkisi ile ilgili literatürde yeterli kaynak bulunmamakla birlikte bu çalışma ile bitkinin toplam fenolik miktarı, antioksidan ve antimikrobiyal aktivitesi kısmen aydınlatılmıştır. Araştırmada, toplam fenolik miktarı yükseldikçe ekstrelerde antioksidan kapasitenin de arttığ1 gözlenmiştir. Saeed ve vd. (2016)'daki çalışmada halk tıbbında kullanılan bazı bitkilerin yüksek antioksidan aktivitelerinin olduğunu belirtmişlerdir. Bununla beraber, kullanımı daha yaygın ve sağlıklı kabul edilen etanol ekstresinin yüksek antioksidan ve antimikrobiyal aktivite potansiyeli barındırması nedeniyle, ileri çalışmalar yapılarak gıda takviyesi veya gida katk1 maddesi olarak kullanılma potansiyelinin irdelenmesi gerekmektedir. Gerekli çalışmalar tamamlandığında bitkinin etanol ekstresinin, piyasada mevcut kimyasalların yerine alternatif doğal madde olarak kullanılma ihtimalinin olabileceği tahmin edilmektedir.

Sonuç olarak bu çalışmanın amacı, Gümüşhane bölgesinde yetişen ve halk tıbbında yaygın olarak kullanılmakta olan Alchemilla ellenbergiana bitkisinin farklı polariteye sahip çözücüler ile hazırlanmış ekstrelerinin gerçekte herhangi bir biyolojik aktiviteye sahip olup olmadığının belirlenmesidir. $\mathrm{Bu}$ sebeple, ekstrelerin antioksidan kapasiteleri ve antimikrobiyal aktiviteleri araştırıldı. Antioksidan kapasite tespiti için benzer çalışmalarda yaygın olarak kullanılmakta olan ABTS ve DPPH yöntemleri; antimikrobiyal aktivite içinse yine ilk olarak 
başvurulan yöntemlerden disk difüzyon yöntemi kullanıldı. Bu çalışmada elde edilen verilerle, ilk kez bu bitkinin biyolojik aktivitesi ortaya konuldu. $\mathrm{Bu}$ yönüyle, çalışma literatüre katkı sağlamıştır ve ileri çalışmalara da yön verebileceği düşünülmektedir.

\section{Kaynaklar}

Altundag, E. ve Ozturk, M., 2011, The 2nd International Geography Symposium GEOMED2010, Ethnomedicinal studies on the plant resources of east Anatolia, Procedia Social and Behavioral Sciences, 19, 756-777.

Brand-Williams, W., Cuvelier, M., Berset, C., 1995, Use of free radical method to evaluate antioxidant activity, Food Science and Technology, 28, 25-30.

CLSI (Clinical and Laboratory Standards), 2007, Performance standards for antimicrobial susceptibility testing. 17th Informational Supplement, M100-S17, 27:1.

Davis, P.H., 1970. Lathyrus L. In: Davis PH (ed.) Flora of Turkey and the East Aegean Islands. Vol. 3, 328-369. Edinburgh: Edinburgh University Press.

Denev, P., Kratchanova, M., Ciz, M., Lojek, A., Vasicek, O., Blazheva, D., Nedelcheva, P., Vojtek, L., ve Hyrsl, P., 2014, Antioxidant, antimicrobial and neutrophil-modulating activities of herb extracts. Acta Biochimica Plonica, 61, 359-367

Gülçin, I., Topal, F., Sarıkaya, S. B. Ö., Bursal, E., Bilsel, G., ve Gören, A.C., 2011, Polyphenol Contents and Antioxidant Properties of Medlar (Mespilus germanica L..Academy of Chemistry of Globe Publications, EISSN:1307-6167.

Güler, B., Manav, E. ve Ugurlu, E., 2015, Medicinal plants used by traditional healers in Bozuyuk (Bilecik-Turkey). Journal of Ethnopharmacology, 173, 39-47.

Hayırlığlu-Ayaz, S., ve Beyazoğlu, O., 1997, The chromosome numbers of five new Alchemilla L. (Rosaceae) records for Turkey. Turkish Journal of Botany, 21, 385-389.

http://www.tubives.com/index.php?sayfa=1\&tax_ $\mathrm{id}=3736$
Izmailow, R., 1981, Karyological studies in species of Alchemilla L. from the Calycinae Bus. (section Brevicaulon Rothm.), Acta Biologica Cracoviensia Series Botanica, 23, 117-130.

Kaya, B. ve Artuvan, Y., 2016, Investigation of antioxidant and antimicrobial effect, phenolic compounds of Alchemilla cimilensis, El-Cezerî Journal of Science and Engineering, 3(1), 27-54.

Nikolova, M., Dincheva, I., Vitkova A. ve Badjakov, I., 2012, Phenolic Acids and Free Radical Scavenging Activity Of Alchemilla Jumrukczalica Pawl., International Journal of Pharmaceutical Sciences and Research, 3(3), 802-804.

Ozbek, H., Acikara, O. B., Keskin, I., Kirmizi, N. I., Ozbilgin, S., Oz, B. E., Kurtul, E., Ozrenk, B. C., Tekin, M. ve Saltan, G., 2017, Evaluation of hepatoprotective and antidiabetic activity of Alchemilla mollis. Biomedicine \& Pharmacotherapy, 86, 172176.

Ozdemir, E. ve Alpınar, K., 2015, An ethnobotanical survey of medicinal plants in western part of central Taurus Mountains: Aladaglar (Nigde-Turkey), Journal of Ethnopharmacology, 166, 53-65.

Paksoy, M.Y., Selvi, S. ve Savran, A., 2015, Ethnopharmacological survey of medicinal plants in Ulukısla (Nigde-Turkey), Journal of Herbal Medicine, 6(1), 42-48.

Re, R., Pellegrini, N., Proteggente, A., Pannala, A., Yang,, M., ve Rice-Evans, C., 1999. Article in Free Radical Biology and Medicine, Doi: 10.1016/S08915849(98)00315-3. Source: Pubmed.

Rothmaler, W., 1937, Systematische Vorarbeiten zu einer Monographie der Gattung Alchemilla (L.) Scop. VII. Aufteilung der Gattung und Nomenklatur, Feddes Repert, 42, 146-173.

Saeed, A., Rehman, S.U., Akram, M., Bhatti, M.Z., Naz, R., Latif, A., Ali, A., Ahmad, A ve Saeed, A., 2016, Evaluation of Antioxidant Effects and Inhibitory Activity of Medicinal Plants against Lipid Peroxidation Induced by Iron and Sodium Nitroprusside in the Mouse Brain. Journal of the Chemical Society of Pakistan, 38, 333. 
Sargin, S. A., 2015, Ethnobotanical survey of medicinal plants in Bozyazı district of Mersin, Turkey. Journal of Ethnopharmacology, 173, 105-126.

Slinkard, K. ve Singleton, V.L., 1977, Total Phenol Analysis: Automation and Comparison with Manual Methods. American Journal of Enology and Viticulture, 28, 49-55.

Şeker Karatoprak, G., İlgün, S. ve Koşar, M., 2017, Phenolic composition, antioxidant and antimicrobial activities of Alchemilla mollis (Buser) Rothm, Chemical Biodiversty, 14, n/a, e1700150. Doi:10.1002/cbdv.201700150.

Usta, C., Yildirim, A. B. ve Turker, A. U., 2014, Antibacterial and antitumour activities of some plants grown in Turkey. Pharmaceutical Biotechnology, Biotechnology \& Biotechnological Equipment, 28(2), 306-315.

Viegi, L., Pieroni, A., Guarrera, P.M. ve Vangelisti, R., 2003, A review of plants used in folk veterinary medicine in Italy as basis for a databank. Journal of Ethnopharmacology, 89(2-3), 221-244.

Zengin, G., Guler, G. O., Aktumsek, A., Ceylan, R., Picot, C. M. N.ve Mahomoodally, M.F., 2015, Enzyme Inhibitory Properties, Antioxidant Activities, and Phytochemical Profile of Three Medicinal Plants from Turkey. Hindawi Publishing Corporation Advances in Pharmacological Sciences, Article ID 410675. 